\title{
Pathological Laughter as an Unusual Manifestation of Acute Stroke
}

\author{
Kyungmi Oh Ho-Jung Kim Byung-Jo Kim Kun-Woo Park Dae-Hie Lee \\ Department of Neurology, Korea University Medical Center, Korea University College of Medicine, \\ Seoul, South Korea
}

Dear Sir,

Poststroke pathological laughter can develop during the acute or chronic stage following cerebral infarcts. The latter delayed-onset type, commonly known as emotionalism, is usually associated with the bilateral involvement of the descending corticobulbar pathways as a component of pseudobulbar palsy $[1,2]$. The former, called 'fou rire prodromique' by Fere in 1903 [3], has been reported in just a few cases and is often confused with the delayed-onset form. This acute-onset type has been considered to be a unique situation rather than a symptom of acute ischemia because the spells of laughter are generally transient, often herald stroke as a single episode [4] or immediately follow the onset of focal deficits [5]. However, the clinical significance of the acute-onset type remains controversial. A recent case report suggested that the acute-onset type of pathological laughter might be a symptom of acute stroke [6]. We report a patient who experienced fluctuating pathological laughter simultaneously with neurological deficits following recurrent bilateral pontine infarcts, which supports the hypothesis that 'the acute-onset type of pathological laughter is one of the symptoms of acute stroke'.

\section{Case Report}

An 80-year-old woman was brought to the hospital complaining of dizziness, dysarthia and a mild right-sided weakness. She had a history of hypertension and stable angina pectoris, which were controlled with antihypertensive and antiplatelet agents. Diffusion-weighted images re-
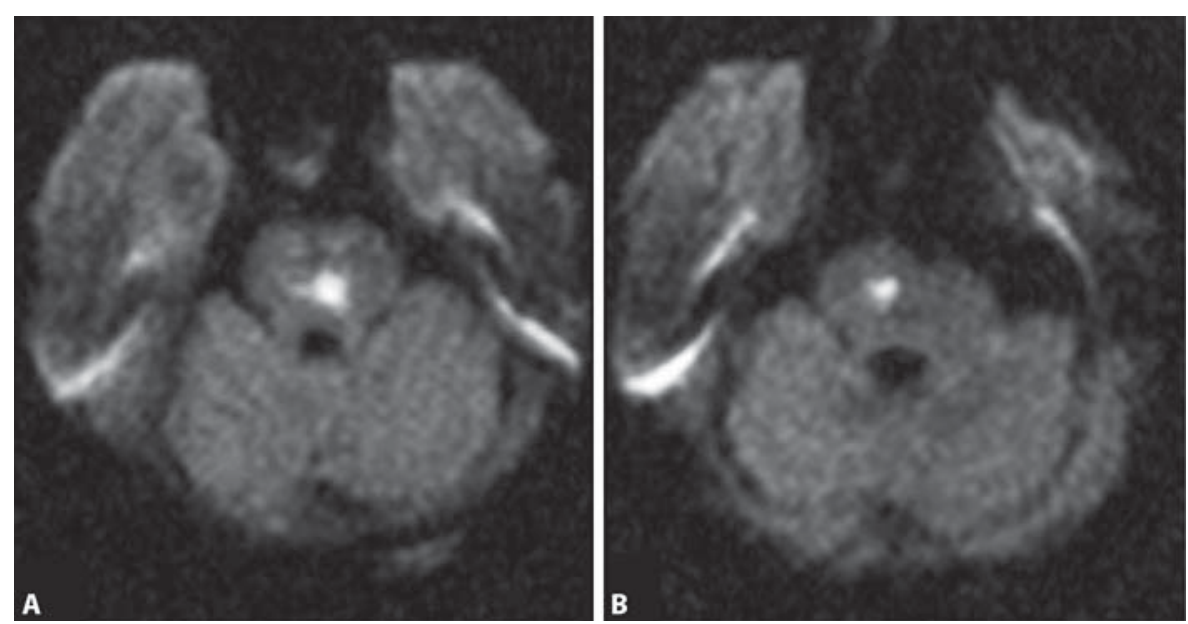

Fig. 1. Diffusion-weighted images. A Diffusion-weighted MRI after the first stroke shows a left ventromedial pontine infarct. B Follow-up diffusion-weighted MRI after the second attack reveals a smaller contralateral pontine infarct.

vealed an acute infarction in the left side of the rostral basis pontis (fig. 1A). CT angiography showed a severe stenosis in the midbasilar artery. Nearly all of her neurological deficits had disappeared by the time she was discharged. However, she complained of general weakness, anorexia and a depressed mood. We prescribed a selective serotonin reuptake inhibitor (SSRI; citalopram $20 \mathrm{mg} /$ day) in addition to the anticoagulation therapy.

Two months later, she experienced sudden dizziness, dysarthria and mild difficulty swallowing. She also noted transient alternating right and left facial paresthesia. She was alert and cooperative. The re- sults of a neurological examination were grossly normal except for a right extensor plantar reflex and a slight gait ataxia. A second diffusion-weighted image revealed an acute right ventromedial pontine infarction, which was smaller than the previous contralateral pontine lesion (fig. 1B). She exhibited unmotivated forced laughter at the onset of the second attack, which occurred most frequently when she spoke. The laughter was also easily triggered by trivial stimuli such as eye contact. These episodes usually persisted from $30 \mathrm{~s}$ to $2 \mathrm{~min}$. She was embarrassed in the presence of explosive laughter despite her feelings of anxiety and depression due to her

\section{KARGER}

Fax +41613061234 E-Mail karger@karger.ch www.karger.com
(C) 2007 S. Karger AG, Basel 0014-3022/08/0592-0083\$24.50/0

Accessible online at: www.karger.com/ene
Byung-Jo Kim, MD, PhD

Department of Neurology

Korea University College of Medicine, No. 126-1 Anam-dong 5-ga

Seongbuk-gu, Seoul 136-705 (Korea)

Tel. +82 2920 6619, Fax +82 2925 2472, E-Mail nukbj@korea.ac.kr 
recurrent stroke attacks. We increased her citalopram dose to $40 \mathrm{mg} / \mathrm{day}$, but the pathological laughter continued. After 2 weeks when her neurological symptoms (i.e. dysarthria and dysphagia) completely improved, the frequency and duration of her pathological laughter began to decrease gradually.

Approximately 1 month after her second attack, she experienced recurrent episodes of sudden neurological symptoms, involving dizziness, dysarthria and gait ataxia sustained for several hours during each attack, which typically occurred several times a day. She could not walk during the transient ischemic attacks due to ataxia and she also experienced several severe spells of pathological laughter. The pathological laughter markedly decreased to baseline when her neurological symptoms and signs disappeared and vice versa. A follow-up diffusion-weighted image did not show any new ischemic lesions. Her fluctuating focal symptoms and the severe cluster of laughter disappeared within 5 days. However, the occasional mild episodes of pathological laughter had completely subsided by the 7-month follow-up.

\section{Discussion}

Acute-onset pathological laughter after pontine infarction has rarely been described, and it is most frequently reported in cases of unilateral lesion [4-8]. In our case, pathological laughter began after bilateral pontine infarctions and fluctuated concurrently with transient ischemic attacks of the territory around the vertebrobasilar artery. The observed pathological laughter exactly matched the clinical course of the other neurological symptoms and the general status of the patient. These findings suggest that pathological laughter may be an unusual ischemic manifestation of bilateral pontine infarction. Gondim et al. [6] had also previously suggested fluctuating pathological laughter as an ischemic symptom to be considered as a heralding sign of extensive brainstem infarction.

Many speculative pathogenic mechanisms of pathological laughter have been suggested. It has been hypothesized that delayed-onset emotionalism is caused by a 'release phenomenon' or 'disinhibition' lesion of the voluntary pathway [1], and by an asynchronous recovery between the voluntary and involuntary laughing systems occurring during the reorganization process [9]. Recently, the role of the pontine serotoninergic raphe nuclei [8], cere- bropontocerebellar pathways [10] and the ischemic ephaptic stimulation of the descending corticopontine/bulbar pathways [6] in pathological laughter was reported. However, no specific mechanism has been suggested for acute-onset pathological laughter. Furthermore, a number of different pathomechanisms for pathological laughter have been suggested in various other neurological diseases [11-14].

SSRIs have been reported as rapid and efficient drugs for the treatment of delayedonset pathological laughter (emotionalism) induced by stroke [15]. However, the responsiveness to SSRIs in cases of acuteonset poststroke pathological laughter remains unclear, especially in the acute phase [16]. To our knowledge, there was only 1 case of acute-onset pathological laughter after cerebellar lesion that showed good response to citalopram during the chronic stage [10]. Our patient's pathological laughter developed after the onset of her second pontine infarction while she was taking an SSRI for depression. Moreover, her pathological laughter continued despite an increase in the SSRI dose, and it fluctuated concurrently with the clinical course of the other neurological deficits. Based on the experience of our case and those previously reported in the literature, several hypotheses could be suggested to explain the occurrence of acute-onset pathological laughter: (a) acute-onset pathological laughter may have a different mechanism than the delayed-onset form; (b) a peculiar serotonin pathway may be induced in patients with previous SSRI use or depression, and (c) bilateral serotonin pathway damage due to recurrent pontine infarctions within short intervals may make it difficult to compensate for the dysfunction of the unilateral serotonin pathway, which is essential for emotion control.

In conclusion, pathological laughter may be the acute ischemic symptom in the patients with bilateral pontine infarcts. The clinical differences between the earlyonset form and the delayed-onset form of poststroke pathological laughter, the differences between pathological laughter after unilateral stroke and after bilateral stroke, and the differences between pathological laughter after supratentorial stroke and after infratentorial stroke must be investigated in future studies in order to elucidate the mechanisms underlying the pathological laughter and to effectively manage the laughter.

\section{References}

1 Wison SAK: Some problems in neurology. II. Pathological laughing and crying. J Neurol Psychopathol 1924;16:299-333.

2 Poeck K: Pathological Laughter and Crying. Amsterdam, Elsevier Science, 1985.

3 Fere MC: Le fou rire prodromique. Rev Neurol 1903;11:353-358.

4 Wali GM: 'Fou rire prodromique' heralding a brainstem stroke. J Neurol Neurosurg Psychiatry 1993;56:209-210.

5 Tei H, Sakamoto Y: Pontine infarction due to basilar artery stenosis presenting as pathological laughter. Neuroradiology 1997;39: 190-191.

6 Gondim FA, Parks BJ, Cruz-Flores S: 'Fou rire prodromique' as the presentation of pontine ischaemia secondary to vertebrobasilar stenosis. J Neurol Neurosurg Psychiatry 2001;71:802-804.

7 Ceccaldi M, Poncet M, Milandre L, Rouyer C: Temporary forced laughter after unilateral strokes. Eur Neurol 1994;34:36-39.

8 Assal F, Valenza N, Landis T, Hornung JP: Clinicoanatomical correlates of a fou rire prodromique in a pontine infarction. J Neurol Neurosurg Psychiatry 2000;69:697-698.

9 Kim JS: Pathologic laughter after unilateral stroke. J Neurol Sci 1997;148:121-125.

10 Parvizi J, Anderson SW, Martin CO, Damasio H, Damasio AR: Pathological laughter and crying: a link to the cerebellum. Brain 2001;124:1708-1719.

11 McCullagh S, Moore M, Gawel M, Feinstein A: Pathological laughing and crying in amyotrophic lateral sclerosis: an association with prefrontal cognitive dysfunction. J Neurol Sci 1999; 169:43-48.

12 Feinstein A, O'Connor P, Gray T, Feinstein $\mathrm{K}$ : Pathological laughing and crying in multiple sclerosis: A preliminary report suggesting a role for the prefrontal cortex. Mult Scler 1999;5:69-73

13 Tateno A, Jorge RE, Robinson RG: Pathological laughing and crying following traumatic brain injury. J Neuropsychiatry Clin Neurosci 2004;16:426-434.

14 Starkstein SE, Migliorelli R, Teson A, Petracca G, Chemerinsky E, Manes F, Leiguarda R: Prevalence and clinical correlates of pathological affective display in Alzheimer's disease. J Neurol Neurosurg Psychiatry 1995;59: 55-60.

15 Andersen G, Vestergaard K, Riis JO: Citalopram for post-stroke pathological crying. Lancet 1993;342:837-839.

16 House AO, Hackett ML, Anderson CS, Horrocks JA: Pharmaceutical interventions for emotionalism after stroke. Cochrane Database Syst Rev 2004;2:CD003690. 